\title{
Novel Autotaxin Inhibitors for the Treatment of Osteoarthritis Pain: Lead Optimization via Structure-Based Drug Design
}

Spencer B. Jones, * Lance A. Pfeifer, Thomas J. Bleisch, Thomas J. Beauchamp, Jim D. Durbin, V. Joseph Klimkowski, ${ }^{\dagger}$ Norman E. Hughes, Christopher J. Rito, Yen Dao, Joseph M. Gruber, ${ }^{\ddagger}$ Hai Bui, Mark G. Chambers, Srinivasan Chandrasekhar, ${ }^{\dagger}$ Chaohua Lin, Denis J. McCann, Daniel R. Mudra, Jennifer L. Oskins, Craig A. Swearingen, Kannan Thirunavukkarasu, and Bryan H. Norman

Lilly Research Laboratories, A Division of Eli Lilly and Company, Indianapolis, Indiana 46285, United States

\section{Supporting Information}

ABSTRACT: In an effort to develop a novel therapeutic agent aimed at addressing the unmet need of patients with osteoarthritis pain, we set out to develop an inhibitor for autotaxin with excellent potency and physical properties to allow for the clinical investigation of autotaxin-induced nociceptive and neuropathic pain. An initial hit identification campaign led to an aminopyrimidine series with an autotaxin $\mathrm{IC}_{50}$ of $500 \mathrm{nM}$. X-ray crystallography enabled the optimization to a lead compound that demonstrated favorable potency $\left(\mathrm{IC}_{50}=\right.$ $2 \mathrm{nM}$ ), PK properties, and a robust PK/PD relationship.

KEYWORDS: Autotaxin, tool molecule, osteoarthritis, LPA

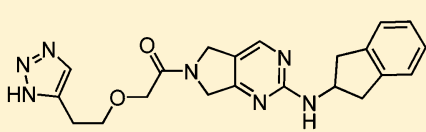

Plasma $\mathrm{IC}_{50} 2.2 \mathrm{nM}$

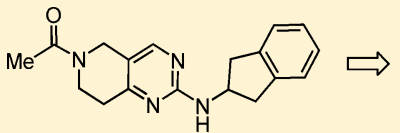

Plasma $\mathrm{IC}_{50} 1.07 \mu \mathrm{M}$
$\mathrm{O}$ steoarthritis (OA) is a highly prevalent disease affecting many adults including more than one out of three individuals aged 65 or older in the United States. ${ }^{1}$ In addition to significant accompanying pain, OA frequently leads to pronounced disability resulting in the loss of work, hospitalization, and joint replacement procedures. ${ }^{2}$ Current first-line pharmacological treatment options for OA focus on reducing inflammation and the associated pain. Nonsteroidal antiinflammatory drugs (NSAIDS) and selective COX-2 inhibitors are among the most prescribed medications for OA pain but unfortunately are also frequently accompanied by gastrointestinal, renal, and CV side effects, limiting their use.

Recently, the role of lyosophosphatidic acid (LPA) in certain inflammatory conditions has been studied. ${ }^{4}$ LPA exists as a number of molecular species that have variable saturated and unsaturated fatty acid chains. ${ }^{5}$ Signaling of LPA through six GPCRs (LPA Receptors 1-6) has been shown to lead to the upregulation of inflammatory cytokines and matrix metalloproteinases, which contribute to the pathogenesis of OA. ${ }^{6}$ LPA signaling has also been associated with many other pathologies, such as pulmonary fibrosis and cancer. ${ }^{7}$

In vivo, the enzyme autotaxin (ATX), with lyosophosopholipase $\mathrm{D}$ activity, is the primary source of extracellular LPA, which results from the cleavage of choline from lysophosphatidylcholine (LPC) (Figure 1). LPA is also produced through action of secreted phospholipases A2 (sPLA2) on phosphatidic acid (PA), although this is believed to be a minor route of extracellular LPA production in vivo. 8

Autotaxin is an extracellular, $125 \mathrm{kDa}$ protein that was originally characterized in 1993 by Stracke et al. as a motility stimulating protein. ${ }^{10}$ In 2002, Umezu-Goto and co-workers demonstrated that ATX was the same protein as a known

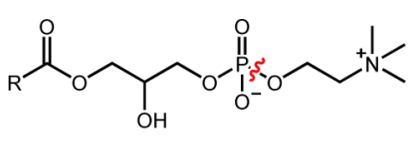

lysophosphatidylcholine (LPC)
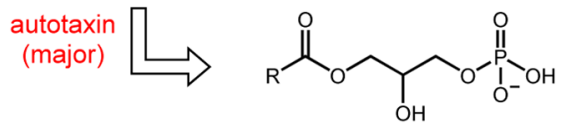

lysophosphatidic acid (LPA)
Figure 1. Two biosynthetic routes of lysophosphatidic acid (LPA) production. R groups on lipids = various unsaturated and saturated fatty acid chains.

lysophopholipase D enzyme, which catalyzed the conversion of LPC to LPA. ${ }^{11}$ Autotaxin is a multidomain protein with two Nterminal somatomedin B-like domains, a centrally located phosphodiesterase domain, and a catalytically inactive nuclease-like domain on the C-terminal region. It is expressed in four main isoforms $(\mathrm{ATX} \alpha-\delta)$ with largely unknown differential functionality in vivo. ${ }^{7}$ The catalytic domain of ATX comprises two zinc ions coordinated with histidine and aspartic acid residues with a threonine alcohol serving as the nucleophile. A large hydrophobic pocket and hydrophilic groove accommodate the various lipophilic LPC species and likely position the choline group in the vicinity of the zinc ions and the phosphate group proximal to the secondary alcohol of the threonine residue.

Received: May 18, 2016

Accepted: July 25, 2016

Published: August 2, 2016 
Structures of several LPA species with mouse ATX have been published illustrating this interaction (Figure 2). ${ }^{12}$

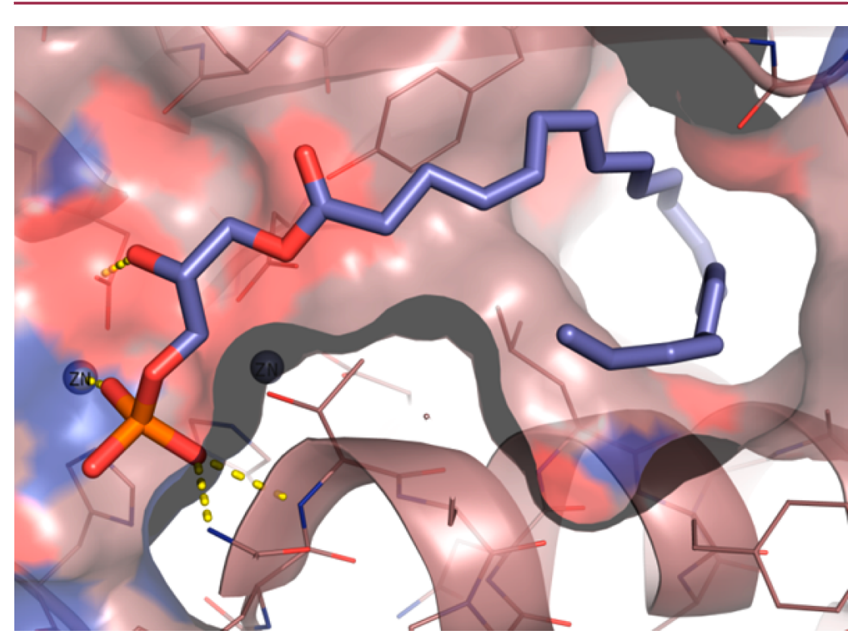

Figure 2. Cocrystal structure of LPA 22:6 bound to mouse autotaxin. ${ }^{12}$

In an effort to enable clinical investigation of the connectivity between human OA pain and autotaxin induced LPA generation, we set out to design a small molecule inhibitor of this enzyme. Two biochemical assays were developed to enable characterization of the autotaxin inhibitors: an LPC coupled enzyme assay and a human plasma assay. The LPC coupled assay uses an enzyme cocktail consisting of autotaxin, choline oxidase, and horseradish peroxidase to enable a fluorescent readout of LPA production via oxidation of the choline byproduct. The human plasma assay utilizes human donor plasma with endogenous autotaxin and LPC substrates. The LPA formed during the course of the assay is quantified by mass spectrometry. The plasma assay has the advantage of accounting for plasma protein binding. Indeed, a potency shift was observed when moving from the LPC to plasma assay in a manner that correlated with plasma protein binding.

Following a traditional high-throughput screen of the Lilly compound collection, we identified the aminopyrimidine $\mathbf{1}$, which demonstrated favorable starting potencies in the LPC coupled enzyme assay and human plasma assay (Table 1). X-ray crystallography studies with compound $\mathbf{1}$ revealed numerous favorable interactions with the protein backbone (Figure 3). Specifically, the indane group of 1 effectively occupies the hydrophobic pocket and forms a T-shaped $\pi-\pi$ interaction with Phe273. In addition, donor and acceptor hydrogen bonds are observed from the aminopyrimidine N,NH atoms to the Trp275 and Phe273 backbone residues. Finally, an additional $\pi-\pi$ interaction between the electron-rich phenol of Tyr306 and the electron-deficient pyrimidine ring is observed.

The crystal structure also revealed the terminal acetamide did not interact with the protein backbone and was over $8 \AA$ from the catalytic zinc ion. Limited SAR within a closely related aminopyrimidine series (data not shown) revealed that substitution of either of the nitrogen atoms involved in hydrogen bonding for carbon resulted in significantly diminished potency.

In 2010, researchers at Pfizer disclosed an inhibitor of autotaxin known as PF-8380 (Chart 1). This inhibitor was reported to have low nanomolar activity in an LPC enzyme assay and $100 \mathrm{nM} \mathrm{IC}_{50}$ in a human whole blood assay. ${ }^{13}$ In our laboratories, PF-8380 confirmed potency of 8.4 and $44 \mathrm{nM}$ in our LPC coupled enzyme and plasma assays, respectively. An
Table 1. Zinc-Binding Group SAR

\begin{tabular}{|c|c|c|c|c|c|}
\hline Compd & $\mathrm{R}$ & $\mathrm{n}$ & $\begin{array}{c}\mathrm{LPC} \mathrm{IC}_{50} \\
(\mathrm{nM})^{\mathrm{a}}\end{array}$ & $\begin{array}{c}\text { Plasma IC } C_{50} \\
(n M)^{a}\end{array}$ & $\begin{array}{l}\text { pKa } \\
\left(\text { calc }^{\mathrm{b}}\right.\end{array}$ \\
\hline 1 & & 1 & $\begin{array}{c}520 \pm 66 \\
\text { (4) }\end{array}$ & $\begin{array}{c}1070 \pm 200 \\
\text { (2) }\end{array}$ & -- \\
\hline 2 & & 1 & $\begin{array}{c}2.5 \pm 0.47 \\
\text { (6) }\end{array}$ & $\begin{array}{c}42 \pm 1.6 \\
\text { (2) }\end{array}$ & 9.3 \\
\hline 3 & & 1 & $\begin{array}{c}2.2 \pm 0.21 \\
\text { (3) }\end{array}$ & $\begin{array}{c}6.3 \pm 1.31 \\
\text { (3) }\end{array}$ & 9.9 \\
\hline 4 & & 1 & $\begin{array}{l}79 \\
\text { (1) }\end{array}$ & $\begin{array}{l}92 \\
\text { (1) }\end{array}$ & 10.9 \\
\hline 5 & & 1 & $\begin{array}{l}24 \\
(1)\end{array}$ & $\begin{array}{l}118 \\
(1)\end{array}$ & 5.1 \\
\hline 6 & & 1 & $\begin{array}{l}4.8 \\
\text { (1) }\end{array}$ & $\begin{array}{l}7.2 \\
(1)\end{array}$ & $\begin{array}{c}6.8 \\
\text { (prot.) }\end{array}$ \\
\hline 7 & & 1 & $\begin{array}{l}10 \\
\text { (1) }\end{array}$ & $\begin{array}{l}34 \\
(1)\end{array}$ & $\begin{array}{c}7.4 \\
\text { (prot.) }\end{array}$ \\
\hline 8 & & 1 & $\begin{array}{l}123 \\
(1)\end{array}$ & $\begin{array}{l}691 \\
(1)\end{array}$ & $\begin{array}{c}14.6 \\
(2.5 \\
\text { prot.) }\end{array}$ \\
\hline 9 & & 0 & $\begin{array}{c}<1.7 \\
(6)\end{array}$ & $\begin{array}{c}2.2 \pm 0.22 \\
\text { (5) }\end{array}$ & 9.2 \\
\hline
\end{tabular}

${ }^{a}$ Values are reported as arithmetic means with standard deviations. Number of replicates in parentheses. ${ }^{b}$ Side chain $\mathrm{p} K_{\mathrm{a}}$ calculated using Marvin $\mathrm{p} K_{\mathrm{a}}$ plugin (www.chemaxon.com, ChemAxon Kft, Budapest, Hungary).

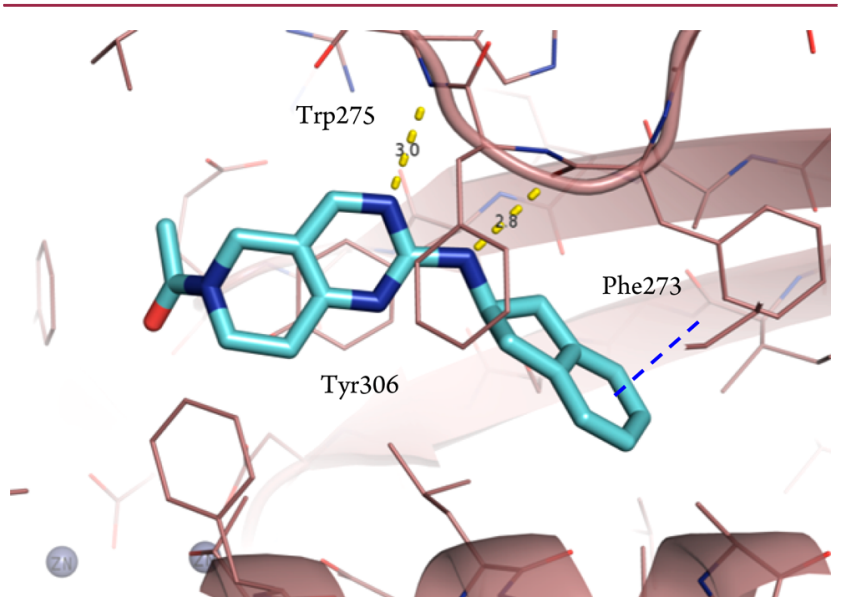

Figure 3. Cocrystal structure of $\mathbf{1}$ bound to rat autotaxin. Hydrogen bond distances shown in $\AA$.

internally solved crystal structure of PF-8380 with autotaxin is shown in Figure 4. The lipophilic dichlorophenyl group of PF8380 anchors the molecule within the hydrophobic pocket with 


\section{Chart 1. Literature Autotaxin Inhibitor PF-8380}<smiles>O=C(CCN1CCN(C(=O)OCc2cc(Cl)cc(Cl)c2)CC1)c1ccc2[nH]c(=O)oc2c1</smiles>

PF-8380

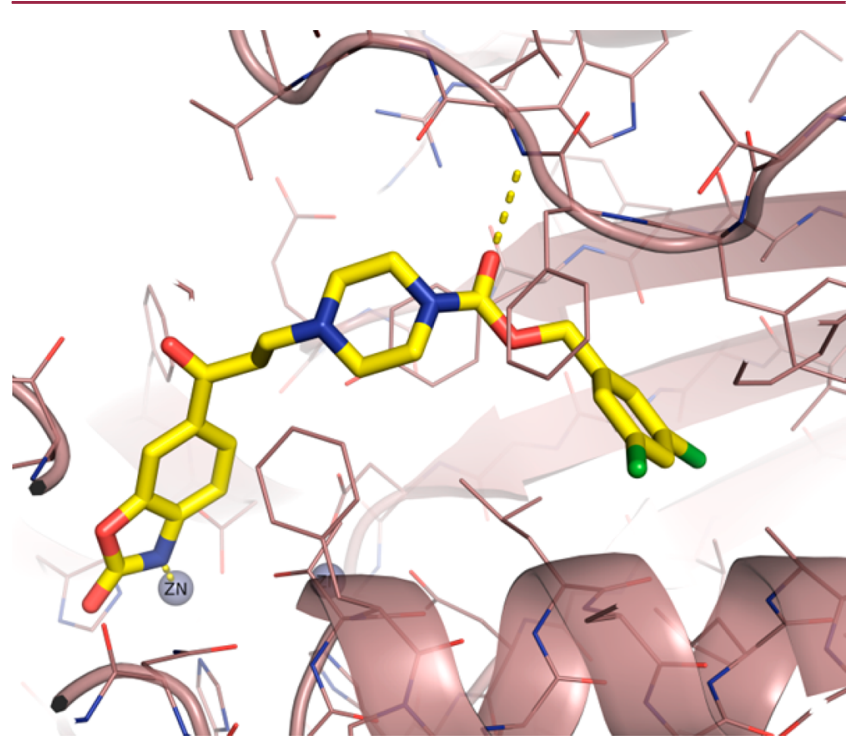

Figure 4. Cocrystal structure of PF-8380 bound to rat autotaxin.

the carbamate carbonyl acting as a hydrogen bond acceptor to Trp275 NH. Notably, PF-8380 extends through the hydrophilic core and the benzoxazolone nitrogen engages the catalytic zinc ion via an electrostatic interaction, presumably responsible for the increased potency of PF-8380 relative to the aminopyrimidine 1 .

In an effort to improve potency within our series, we also recognized the potential to interact directly with the catalytic zinc center. Indeed, coupling a propionylbenzoxazolone group onto the core piperidine afforded compound 2 , which demonstrated $2.5 \mathrm{nM} \mathrm{IC}_{50}$ in the LPC coupled enzyme assay but, similar to PF8380, notably weaker potency in the plasma assay ( $\left.41 \mathrm{nM} \mathrm{IC}_{50}\right)$. A cocrystal structure of $\mathbf{2}$ with autotaxin demonstrated minimal shift from the parent $\mathbf{1}$ with the flexible linker enabling the benzoxazolone to interact with the catalytic zinc ion (Figure 5).

Despite achieving a significant increase in potency relative to the ligand ID hit (1), compound 2 was plagued with poor solubility, high microsomal metabolism, and very poor rat PK, which precluded further development. Moreover, attempts to improve physical properties and activity in a closely related series through substitution of the indane for alternative hydrophobic pocket binding groups was not successful as this led to compounds with weaker plasma activity and higher cLogPs (see Table 2).

However, encouraged by the potency breakthrough compound 2 afforded, we examined a number of potential zincbinding groups as an alternative for the benzoxazolone with varying linker lengths. Ultimately, a linker length of four atoms proved ideal with longer linkers being equipotent and shorter linker lengths being significantly less potent. Among those tested (Table 1) were triazoles $(3,4)$, tetrazole $(5)$, imidazoles $(6,7)$, and pyrazole (8). After extensive exploration, the 1,2,3-triazoles and 1 - and 4-imidazoles emerged as the most potent compounds

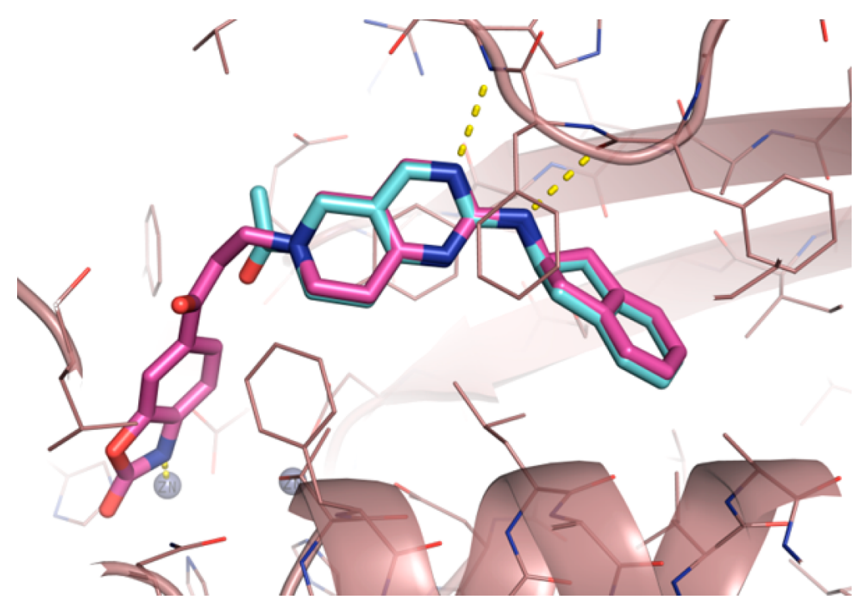

Figure 5. Cocrystal structure overlays of 1 and 2 bound to rat autotaxin.

Table 2. Hydrophobic Pocket SAR

(calc)

${ }^{a}$ Calcuated using Marvin $\mathrm{p} K_{\mathrm{a}}$ plugin (www.chemaxon.com, ChemAxon Kft, Budapest, Hungary). $N=1$ for all LPC and Plasma $\mathrm{IC}_{50} \mathrm{~s}$.

with these alternative zinc-binding groups. While we were able to obtain X-ray structures of these alkyl-linked heterocyclic inhibitors, no electron density was ever observed for the linker region, presumably due to the flexibility and mobility within this section of the inhibitor.

A SAR analysis revealed a pronounced correlation between the $\mathrm{p} K_{\mathrm{a}}$ of the zinc-binding group and the relative potency (LPC $\left.\mathrm{IC}_{50}\right)$ with a maximum occurring at $\mathrm{p} K_{\mathrm{a}} \approx 8.5-10.5$ for acidic heterocycles and $\mathrm{p} K_{\mathrm{a}} \approx 6-8$ for basic heterocycles. These observations can potentially be explained using insights from Duca and co-workers' work on the metalloproteinase TNF- $\alpha$ converting enzyme (TACE). ${ }^{14}$ They showed that binding of hydroxamic and carboxylic acids to the Lewis-acidic zinc ion within TACE results in a decrease in $\mathrm{p} K_{\mathrm{a}}$ of the binding group by 2-3 units. Extrapolation of these findings to our system led to the following theory regarding optimal $\mathrm{p} K_{\mathrm{a}}$ for ATX inhibitors (Figure 6). In the case of acidic heterocycles, in order to maximize the binding affinity, the heterocycle would ideally undergo deprotonation only upon coordination to the zinc ion because prior deprotonation (e.g., $\mathrm{p} K_{\mathrm{a}}<\sim 7.4$ ) would impose a higher desolvation penalty. Alternatively, if the $\mathrm{p} K_{\mathrm{a}}$ were too high (e.g., $\mathrm{p} K_{\mathrm{a}}>\sim 11$ ), the Lewis acid assisted reduction in $\mathrm{p} K_{\mathrm{a}}$ would 

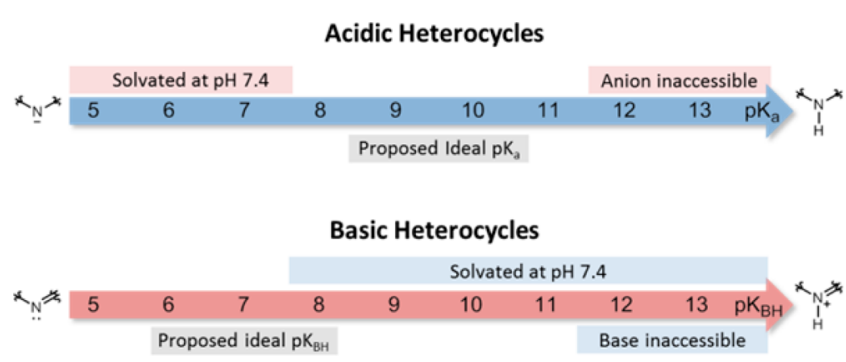

Figure 6. Rationale of $\mathrm{p} K_{\mathrm{a}}$ dependency on autotaxin inhibitor potency.

be insufficient to enable deprotonation of the heterocycle at physiological $\mathrm{pH}$.

In the case of basic zinc-binders, the more basic heterocycles are protonated and hence require greater desolvation energy at physiologic $\mathrm{pH}$. As a result, the ideal basic heterocycle would be able to engage the zinc ion without significant energetic penalty by being predominantly neutral at physiological $\mathrm{pH}$ (e.g., $\mathrm{p} K_{\mathrm{a}}<$ $\sim 8$ ). However, as the $\mathrm{p} K_{\mathrm{BH}}$ decreases, binding to the zinc becomes energetically less favorable due to an increasing mismatch between the HOMO (nitrogen lone pair electrons) and LUMO (zinc ion). Overall, this hypothesis correlates empirically with the observed binding affinity for numerous heterocycles.

Further optimization of this series culminated in the identification of triazole 9. Indeed, substitution for the [6,5]pyrrolopyrimidine core ring system and inclusion of oxygen within the alkyl linker improved the ADME properties and afforded an inhibitor of autotaxin with $2 \mathrm{nM} \mathrm{IC}_{50}$ in both the enzyme and plasma assays.

The synthesis of 9 was completed as shown in Scheme 1. Commercially available chloropyrimidine $\mathbf{1 4}$ was coupled to 2aminoindane (15) via an $S_{N} A r$ reaction to give aminopyrimidine 16. Acid-mediated deprotection of the BOC group afforded the dihydropyrrole 17 , which was then acylated with 2-chloroacetyl chloride to give the $\alpha$-chloroacetamide 18. Finally, alkylation of 18 with 3-butyn-1-ol, gave the alkyne 19, which was converted to triazole 9 via a copper(I)-catalyzed azide-alkyne cycloaddition. $^{15}$

Encouraged by its in vitro profile, 9 was evaluated in a rat PK/ PD model that measured the reduction in plasma LPA vs drug exposure (Figure 7, Table 3). We anticipated target engagement and lower LPA levels when exposures exceeded the plasma $\mathrm{IC}_{80}$. Due to the extremely short half-life of LPA in vivo, ${ }^{16}$ autotaxin inhibition is accompanied by a nearly real-time reduction in

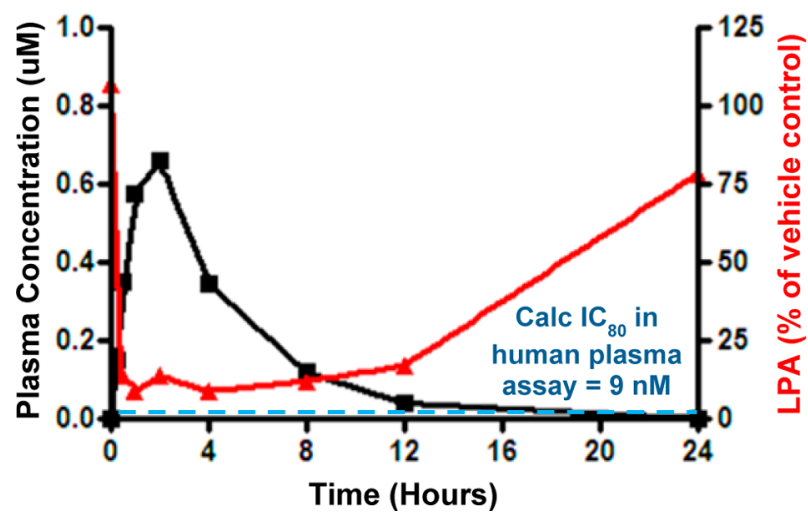

Figure 7. Rat PK/PD $(10 \mathrm{mg} / \mathrm{kg})$ experiment illustrates the correlation between plasma drug concentration and reduction in plasma LPA.

Table 3. Pharmacokinetic Properties of 9 in Rat $^{a}$

\begin{tabular}{ll}
\multicolumn{1}{c}{ parameters } & compound 9 \\
I.V. dose $(\mathrm{mg} / \mathrm{kg})$ & 1.0 \\
$T_{1 / 2}$, iv $(\mathrm{h})$ & $1.14 \pm 0.12$ \\
$V_{\mathrm{dss}}(\mathrm{L} / \mathrm{kg})$ & $1.4 \pm 0.37$ \\
PO dose $(\mathrm{mg} / \mathrm{kg})$ & 10 \\
$C_{\max }(\mathrm{nM})$ & $660 \pm 120$ \\
$\mathrm{AUC}(\mathrm{nM} \cdot \mathrm{h})$ & $3440 \pm 340$ \\
$\% F$ & $23 \pm 4$
\end{tabular}

${ }^{a}$ Rat PK data is mean $\pm \mathrm{SD}, n=3$. Formulation: PO, $40 \% \mathrm{HPBCD}$ in water; IV, DMA 10\%/EtOH 15\%/propylene glycol 30\%/ $\mathrm{NaPO}_{4}$ buffer ( $\mathrm{pH} 8) 25 \mathrm{mM}$.

plasma LPA. After a single oral dose $(10 \mathrm{mg} / \mathrm{kg})$ in normal rats, plasma concentrations of drug and LPA were monitored over 24 h. As shown in Figure 7, early time points demonstrated high plasma concentrations of 9 and concomitant low concentrations of LPA. As expected, as the plasma drug concentration decreased, LPA levels returned to near normal levels. Plasma concentrations of 9 exceeded the calculated $\mathrm{IC}_{80}$ for more than $12 \mathrm{~h}$ with concurrent reduction in LPA over the same period. The robust $\mathrm{PK} / \mathrm{PD}$ relationship of $\mathbf{9}$ has translated into efficacy in a number of animal models, the details of which have been reported in an additional communication. ${ }^{17}$

In summary, we have utilized structural information to facilitate the design of highly potent autotaxin inhibitors. Through the course of this investigation, we identified a strong correlation between the $\mathrm{p} K_{\mathrm{a}}$ of the zinc-binding group and the

Scheme 1. Synthesis of $9^{a}$<smiles>CC(C)(C)OC(=O)N1Cc2cnc(Cl)nc2C1</smiles>

14<smiles>NC1Cc2ccccc2C1</smiles>

15
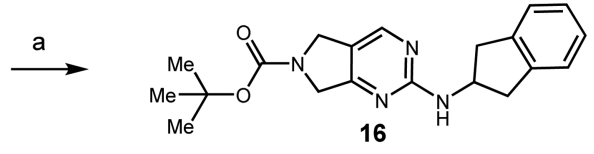

16

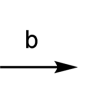<smiles>OCC1Cc2ccccc2C1</smiles><smiles>C1C[Te]C1</smiles>
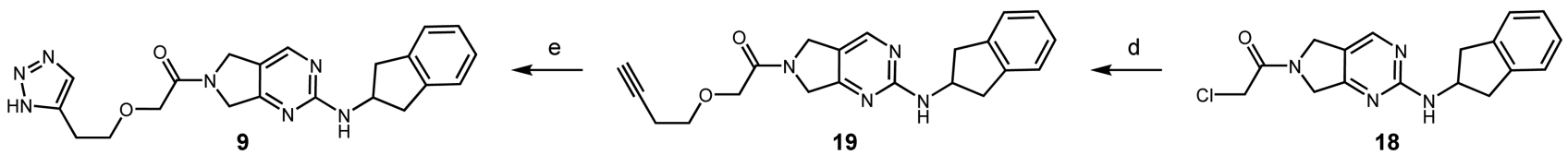

18

${ }^{a}$ Reagents and conditions: (a) $i \operatorname{Pr}_{2} \mathrm{EtN}, \mathrm{NMP}, 80{ }^{\circ} \mathrm{C}, 75 \%$; (b) $5 \mathrm{~N} \mathrm{HCl}_{(\mathrm{aq}}$, THF, $50{ }^{\circ} \mathrm{C}, 80 \%$; (c) 2-chloroacetyl chloride, $\mathrm{Et}_{3} \mathrm{~N}, \mathrm{CH}_{2} \mathrm{Cl}_{2}, 23{ }^{\circ} \mathrm{C}$, 84\%; (d) 3-butyn-1-ol, $\mathrm{NaH}$, THF, $0{ }^{\circ} \mathrm{C}, 23 \%$; (e) $\mathrm{CuSO}_{4} \cdot 5 \mathrm{H}_{2} \mathrm{O}$, L-sodium ascorbate, $\mathrm{TMSN}_{3}, \mathrm{DMF}, \mathrm{H}_{2} \mathrm{O}, 90{ }^{\circ} \mathrm{C}, 30 \%$. 
potency of the compounds. Further optimization of the core and linker region of the inhibitors led to the identification of 9 , a $2 \mathrm{nM}$ inhibitor of autotaxin in the human plasma assay with a robust $\mathrm{PK} / \mathrm{PD}$ relationship. Based partially on this data, compound 9 was identified as a valuable tool for investigating the role of autotaxin in OA pain.

\section{ASSOCIATED CONTENT}

\section{S Supporting Information}

The Supporting Information is available free of charge on the ACS Publications website at DOI: 10.1021/acsmedchemlett.6b00207.

Procedures for the preparation of 1-13, crystallization and structural determination, and biological assays (PDF) Autotaxin_1 (PDB)

Autotaxin_pf8380 (PDB)

Autotaxin_2(PDB)

\section{Accession Codes}

Coordinates and structure factors are available from the Protein Data Bank with accession codes 5L0K, 5L0B, and 5L0E for $r$ ATX/PF-8380, $r \mathrm{ATX} / \mathbf{1}$, and $r \mathrm{ATX} / \mathbf{2}$ binary complexes, respectively.

\section{AUTHOR INFORMATION}

\section{Corresponding Author}

*E-mail: jonessp@lilly.com. Tel: +1-317-277-5543.

\section{Present Address}

${ }^{\ddagger}$ Dow AgroSciences, Zionsville, Indiana 46268, United States.

\section{Notes}

The authors declare no competing financial interest.

${ }^{\dagger}$ Retired.

\section{ACKNOWLEDGMENTS}

Use of the Advanced Photon Source, an Office of Science User Facility operated for the U.S. Department of Energy (DOE) Office of Science by Argonne National Laboratory, was supported by the U.S. DOE under Contract No. DE-AC0206CH11357. Use of the Lilly Research Laboratories Collaborative Access Team (LRL-CAT) beamline at Sector 31 of the Advanced Photon Source was provided by Eli Lilly and Company, which operates the facility.

\section{ABBREVIATIONS}

OA, osteoarthritis; NSAID, nonsteroidal anti-inflamatory drug; COX-2, cyclooxygenase-2; CV, cardiovascular; LPA, lysophosphatidic acid; GPCR, G protein-coupled receptor; ATX, autotaxin; LPC, lysophosphatidylcholine; sPLA2, secreted phospholipases A2; PA, phosphatidic acid; ID, identification; compd, compound; SAR, structure-activity relationship; $\mathrm{PK}$, pharmacokinetics; TACE, TNF-a converting enzyme; HOMO, highest occupied molecular orbital; LUMO, lowest unoccupied molecular orbital; $\mathrm{ADME}$, absorption distribution metabolism excretion; PD, pharmacodynamics

\section{REFERENCES}

(1) Lawrence, R. C.; Felson, D. T.; Helmick, C. G.; Arnold, L. M.; Choi, H.; Deyo, R. A.; Gabriel, S.; Hirsch, R.; Hochberg, M. C.; Hunder, G. G.; Jordan, J. M.; Katz, J. N.; Kremers, H. M.; Wolfe, F. Estimates of the prevalence of arthritis and other rheumatic conditions in the United States Part II. Arthritis Rheum. 2008, 58, 26-35.
(2) Gabriel, S. E.; Crowson, C. S.; Campion, M. E.; O’Fallon, W. M. Direct medical costs unique to people with arthritis. J. Rheumatol. 1997, 24, 719-25.

(3) Laufer, S. Osteoarthritis therapy-are there still unmet needs? Rheumatology 2004, 43, i9-i15.

(4) Orosa, B.; Garcia, S.; Conde, C. The autotaxin-lysophosphatidic acid pathway in pathogenesis of rheumatoid arthritis. Eur. J. Pharmacol. 2015, 765, 228-233.

(5) Bandoh, K.; Aoki, J.; Taira, A.; Tsujimoto, M.; Arai, H.; Inoue, K. Lysophosphatidic acid (LPA) receptors of the EDG family are differentially activated by LPA species. FEBS Lett. 2000, 478, 159-165.

(6) Mototani, H.; Lida, A.; Nakajima, M.; Furuichi, T.; Tsunoda, T.; Sudo, A.; Kotani, A.; Uchida, A.; Ozaki, K.; Tanaka, Y.; Nakamura, Y.; Tanaka, T.; Notoya, K.; Ikegawa, S. A functional SNP in EDG2 increases susceptibility to knew osteoarthritis in Japanese. Hum. Mol. Genet. 2008, 17, 1790-1797.

(7) Perrakis, A.; Moolenaar, W. H. Autotaxin: structure-function and signaling. J. Lipid Res. 2014, 55, 1010-1018.

(8) Cai, Q.; Zhao, Z.; Antalis, C.; Yan, L.; Priore, G. D.; Hamed, A. H.; Stehman, F. B.; Schilder, J. M.; Xu, Y. Elevated and secreted phospholipase A2 activities as new potential therapeutic targets in human epithelial ovarian cancer. FASEB J. 2012, 26, 3306-3320.

(9) Aoki, J.; Inoue, A.; Okudaira, S. Two pathways for lysophosphatidica acid production. Biochim. Biophys. Acta, Mol. Cell Biol. Lipids 2008 $1781,513-518$

(10) Stracke, M. L.; Krutzsch, H. C.; Unsworth, E. J.; Arestad, A.; Cioce, V.; Schiffmann, E.; Liotta, L. A. Identification, purification, and partial sequence analysis of autotaxin, a novel motility-stimulating protein. J. Biol. Chem. 1992, 267, 2524-2529.

(11) Umezu-Goto, M.; Kishi, Y.; Taira, A.; Hama, K.; Dohmae, N.; Takio, K.; Yamori, T.; Mills, G. B.; Inoue, K.; Aoki, J.; Arai, H. Autotaxin has lysophospholipase $\mathrm{D}$ activity leading to tumor cell growth and motility by lysophosphatidic acid production. J. Cell Biol. 2002, 158, 227-233.

(12) Nishimasu, H.; Okudaira, S.; Hama, K.; Mihara, E.; Dohmae, N.; Inoue, A.; Ishitani, R.; Takagi, J.; Aoki, J.; Nureki, O. Crystal structure of autotaxin an insight into GPCR activation by lipid mediators. Nat. Struct. Mol. Biol. 2011, 18, 205-213.

(13) Gierse, J.; Thorarensen, A.; Beltey, K.; Bradshaw-Pierce, E.; Cortes-Burgos, L.; Hall, T.; Johnston, A.; Murphy, M.; Nemirovskiy, O.; Ogawa, S.; Pegg, L.; Pelc, M.; Prinsen, M.; Schnute, M.; Wendling, J.; Wene, S.; Weinberg, R.; Wittwer, A.; Zweifel, B.; Masferrer, J. A novel autotaxin inhibitor reduces lysophosphatidic acid levels in plasma and the site of inflammation. J. Pharmacol. Exp. Ther. 2010, 334, 310-317.

(14) Cross, J. B.; Duca, J. S.; Kaminski, J. J.; Madison, V. S. The active site of a zinc-dependent metalloproteinase influences the computed $\mathrm{pKa}$ of ligands coordinated to the catalytic zinc ion. J. Am. Chem. Soc. 2002, 124, 11004-11007.

(15) Aher, N. G.; Pore, V. S.; Mishra, N. N.; Kumar, A.; Shukla, P. K.; Sharma, A.; Bhat, M. K. Synthesis and antifungal activity of 1,2,3-triazole containing fluconazole analogues. Bioorg. Med. Chem. Lett. 2009, 19, $759-763$.

(16) Albers, H. M.; Dong, A.; van Meeteren, L. A.; Egan, D. A.; Sunkara, M.; van Tilburg, E. W.; Schuurman, K.; van Tellingen, O.; Morris, A. J.; Smyth, S. S.; Moolenar, W. H.; Ovaa, H. Boronic acidbased inhibitor of autotaxin reveals rapid turnover of LPA in the circulation. Proc. Natl. Acad. Sci. U. S. A. 2010, 107, 7257-7262.

(17) Thirunavukkarasu, K.; Swearingen, C.; Oskins, J.; Lin, C.; Bui, H.; Jones, S.; Pfeifer, L.; Norman, B.; Mitchell, P.; Chambers, M. Manuscript under review. 